\title{
PERANCANGAN DAN IMPLEMENTASI JARINGAN FAILOVER MENGGUNAKAN PROTOKOL SPANNING TREE PADA PT. PLN UP3B KALIMANTAN TIMUR
}

\author{
Djumhadi ${ }^{1}$, Riovan Styx Roring ${ }^{2}$ \\ Dosen Universitas Mulia ${ }^{1}$,Dosen Universitas Mulia ${ }^{2}$ \\ Jl. ZA Maulani No.09 Bukit Damai Sejahtera Balikpapan Kalimanatan Timur \\ Telp. 0542-766766 \\ Sur-el : djumhadi@universitasmulia.ac.id ${ }^{1}$, styxroring@gmail.com²
}

\begin{abstract}
The availability of electricity is very reliable as a main of supporting component in development progress and economic growth. PT. PLN as an authorized implementation unit for distributing and regulating electricity supply from the power plant to the transmission line requires a reliable network communication system for its operations, as a facility to connect all of its main substations. The disruption of the information network is an important thing that must be avoided in the company so that it does not interfere the distribution of information. The reliable information distribution methods from the main office to the branch offices should be failover that uses backup links in all branch offices as a solution to keep the information network system reliable by using the protocol of spanning tree and VLAN configuration on the routers and manageable switches. Having used the failover method on a network system, it is expected to help the company to always keep reliable in distributing information to all substations so that information loss can be drastically reduced.
\end{abstract}

Keywords: Failover, Spanning Tree, Backup-link, PLN

\begin{abstract}
Abstrak : Ketersediaan tenaga listrik sangat diandalkan sebagai komponen pendukung utama dalam perkembangan pembangunan dan kemajuan ekonomi. PT.PLN sebagai unit pelaksana yang berwenang dalam menyalurkan dan mengatur pasokan listrik dari pembangkit sampai ke jalur transmisi memerlukan sistem komunikasi jaringan yang handal untuk operasionalnya, sebagai sarana penghubung seluruh gardu induknya. Terputusnya jaringan informasi merupakan hal penting yang harus dihindari dalam perusahaan sehingga tidak menggangu distribusi informasi.Metode distribusi informasi yang andal dari kantor utama ke kantor cabang menjadi hal yang harus Failover yang menggunakan backup link pada seluruh kantor cabang menjadi solusi untuk menjaga keandalan sistem jaringan informasi dengan memanfaatkan protokol spanning tree dan konfigurasi vlan pada router dan switch manageable yang digunakan.Dengan menggunakan metode failover pada system jaringan diharapkan dapat membantu perusahaan untuk selalu andal dalam mendistribusikan informasi ke seluruh unit gardu induk sehingga putusnya informasi dapat kurangi seminimal mungkin.
\end{abstract}

Kata Kunci : Failover, Spanning Tree, Backup-Link, PLN

\section{PENDAHULUAN}

PT.PLN (Persero) unit Penyaluran dan Pusat Pengatur Beban (UP3B) Kalimanta Timur merupakan unit pelaksana yang berwenang untuk menyalurkan dan mengatur pasokan beban dari pembangkit sampai ke jalur transmisi sehingga terdapat sistem komunikasi dan jaringan untuk keperluan operasional yang terhubung ke seluruh gardu induk yang tersebar di Provinsi Kalimantan Timur melalui media fiber optic yang dilewatkan pada tower SUTT (Saluran Udara Tegangan Tinggi). Ketersediaan listrik yang dapat diandalkan adalah salah satu komponen penting penunjang pembangunan dan pertumbuhan ekonomi, oleh karena itu penyaluran listrik di Kalimantan 
Timur harus memenuhi kebutuhan serta mampu mengimbangi beban listrik yang selalu bertambah. Kebutuhan tenaga listrik yang harus terjamin, maka perlu dilakukan beberapa pemantauan / pengawasan baik dari keandalan jaringan kelistrikan maupun daya yang dihasilkan dari pembangkit. Masalah yang sering terjadi adalah terputusnya saluran komunikasi yang melalui jaringan fiber optic yang menghubungkan gardu induk melalui media transmisi SUTT sehingga mengakibatkan seluruh peralatan jaringan yang terdapat di gardu induk tersebut maupun digardu induk setelahnya terputus dikarenakan tidak dapat berkomunikasi dengan server yang terdapat di kantor PT PLN (Persero) UP3B Kaltim karena semua informasi bersumber dari server tersebut. Kondisi geografis Provinsi Kalimantan Timur yang extreme sangat mempengaruhi recovery time ketika terjadi permasalahan tersebut, sehingga perdampak terhadap operasional perusahaan dan pengendalian sistem kelistrikan. Berdasar keadaan tersebut perlu disiapkan suatu sistem jaringan yang dapat mengatasi hal tersbut yaitu dengan melakukan metode failover [1] ketika terjadi fiber cut pada jalur utama dan secara otomatis akan mengalihkan traffic [2] menggunakan jalur alternatif. Sehingga tidak berdampak terhadap operasional perusahaan dan pengendalian sistem tenaga listrik

\section{METODOLOGI PENELITIAN}

Failover [3][4] adalah sebuah metode yang menerapkan beberapa jalur koneksi untuk mencapai suatu network tujuan. Namun dalam keadaan normal hanya ada satu link yang digunakan. Link yang lain berfungsi sebagai cadangan dan hanya akan digunakan apabila link utama terputus. Spanning Tree Protocol (STP) [9] adalah Layer 2 (dua) data link manajemen protokol yang menyediakan redundansi jalan sementara untuk mencegah masalah loop dalam jaringan dan bagaimana STP telah berkembang menjadi sebuah protokol yang cepat menghitung port mana harus diblokir sehingga jaringan VLAN (Virtual $L A N)$ berbasis STP disimpan bebas dari loop lalu lintas. Tugas utama dari STP antaranya menghentikan terjadinya loop-loop network pada network layer 2 (bridge atau switch). STP secara terus menerus memonitor network untuk menemukan semua link, memastikan bahwa tidak ada loop yang terjadi dengan cara mematikan semua link yang redundant. STP menggunakan algoritma yang disebut spanning-tree algorithm (STA) untuk menciptakan sebuah topologi database, kemudian mencari dan menghancurkan link-link redundant. Dengan menjalankan STP, frameframe hanya akan diteruskan pada linklink utama yang dipilih oleh STP. Masalah utama yang bisa dihindari dengan adanya STP adalah Broadcast storms. Broadcast storm menyebabkan frame broadcasts atau multicast atau unicast yang destination addressnya belum diketahui oleh switch terus berputarputar (looping) dalam network tanpa henti. Pada gambar 1 adalah contoh sederhana LAN dengan link yang redudant [4]. 


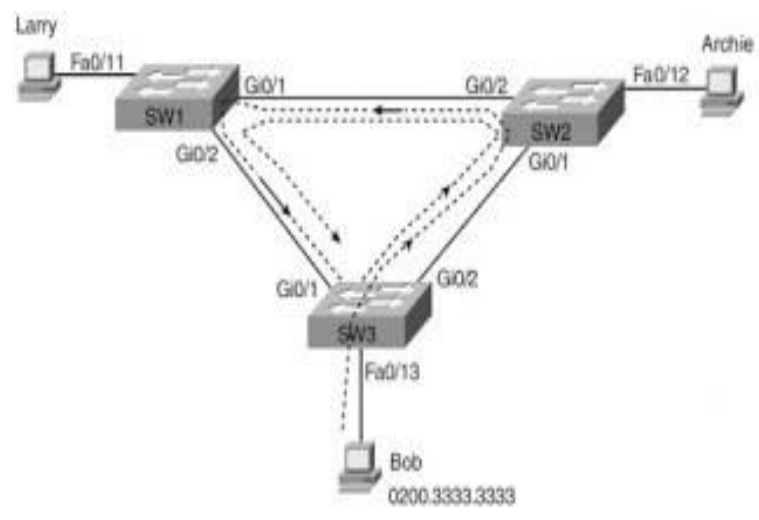

\section{Gambar 1. Redundant Link Looping}

dengan menerapkan metode Spanning Tree Protocol (STP) dapat mencegah terjadinya looping dengan menempatkan setiap port switch pada salah satu status forwarding atau blocking. Interface dengan status forwarding [5] bekerja normal, mem-forward dan menerima frame, sedangkan interface dengan status blocking tidak memproses frame apapun kecuali pesanpesan STP. Semua port yang berada dalam status forwarding disebut berada pada jalur spanning tree (topology STP), sekumpulan port-port forwarding membentuk jalur tunggal dimana frame ditransfer antar-segment. Gambar 2 adalah LAN [7] dengan link redundant yang sudah memanfaatkan STP.

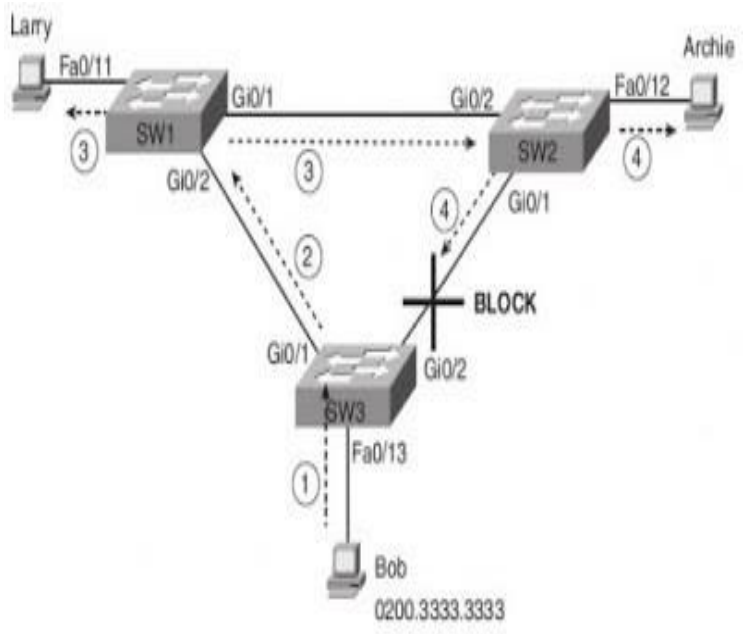

Gambar 2. Redundant Link Blocking
Pada gambar $2 \quad P C$ Bob mengirimkan frame broadcast, frame tidak mengalami looping. PC Bob mengirimkan frame ke SW3 (step 1), kemudian SW3 mem-forward frame hanya ke SW1(step 2), dikarenakan port Gi0/2 dari SW3 berada pada status blocking. Kemudian, SW1 mem-flood frame keluar melalui $\mathrm{Fa} 0 / 11$ dan Gi0/1 (step 3). SW2 mem-flood frame keluar melalui $\mathrm{Fa} 0 / 12$ dan Gi0/1 (step4). Namun, SW3 akan mengabaikan frame yang dikirmkan oleh SW2, karena frame tersebut masuk melalui port Gi0/2 dari switch SW3 yang berada pada status blocking. Dengan topologi STP seperti pada gambar diatas, switch-switch tidak mengaktifkan link antara SW2 dan SW3 untuk keperluan traffick dalam VLAN [6]. Namun, jika link antara SW1 dan SW3 mengalami kegagalan dalam beroperasi, maka STP akan membuat port Gi0/2 pada SW3 menjadi forwarding sehingga link antara SW3 dan SW2 menjadi aktif dan frame tetap bisa ditransfer secara normal dalam VLAN. Cara kerja Spanning Tree Protocol (STP) :

a. Menentukan root bridge [8]

Root bridge dari spanning tree adalah bridge dengan bridge ID terkecil (terendah). Tiap bridge mempunyai unique identifier (ID) dan sebuah priority number yang bisa dikonfigurasi. Untuk membandingkan dua bridge ID [10], priority number yang pertama kali dibandingkan. Jika priority number antara kedua bridge tersebut sama, maka yang akan dibandingkan selanjutnya adalah MAC address. Sebagai contoh, jika switch A (MAC $=0000.0000 .1111) \quad$ dan $\quad B$ MAC $=0000.0000 .2222$ ) memiliki priority 
number yang sama, misalnya 10, maka switch A yang akan dipilih menjadi root bridge. Jika admin jaringan ingin switch $\mathrm{B}$ yang jadi root bridge, maka priority number switch $\mathrm{B}$ harus lebih kecil dari 10.

b. Menentukan least cost paths ke root bridge Spanning tree yang sudah dihitung mempunyai properti yaitu pesan dari semua alat yang terkoneksi ke root bridge dengan pengunjungan (traverse) dengan cost jalur terendah, yaitu path dari alat ke root memiliki cost terendah dari semua paths dari alat ke root. Cost of traversing sebuah path adalah jumlah dari cost-cost dari segmen yang ada dalam path. Beda teknologi mempunya default cost yang berbeda untuk segmensegmen jaringan. Administrator dapat memodifikasi cost untuk pengunjungan segmen jaringan yang dirasa penting.

c. Non-aktifkan root path lainnya

Pada langkah diatas telah ditentukan cost terendah untuk tiap path dari peralatan ke root bridge, maka port yang aktif yang bukan root port diatur menjadi blocked port. Hal ini dilakukan untuk antisipasi jika root port tidak bisa bekerja dengan baik, maka port yang tadinya di blok akan di aktifkan dan kembali lagi untuk menentukan path baru. [7]

Tabel 1. Path Cost Tabel Spanning Tree

\begin{tabular}{lcr}
\hline Bandwidth & $\begin{array}{c}\text { Short Path } \\
\text { Cost Method } \\
\text { Port Cost }\end{array}$ & $\begin{array}{c}\text { Long Path Cost } \\
\text { Method Port } \\
\text { Cost }\end{array}$ \\
\hline 10 Mbps & 100 & $2,000,000$ \\
$100 \mathrm{Mbps}$ & 19 & 200,000 \\
1-Gigabit & 4 & 20,000 \\
Ethernet & & 2,000 \\
10-Gigabit & 2 & \\
Ethernet & & \\
\hline
\end{tabular}

Kelebihan Spanning Tree Protocol (STP)

1. Menghindari Trafic Bandwith yang tinggi dengan mensegmentasi jalur akses melalui switch.

2. Menyediakan Backup / stand by path untuk mencegah loop dan switch yang failed / gagal.

3. Mencegah looping.

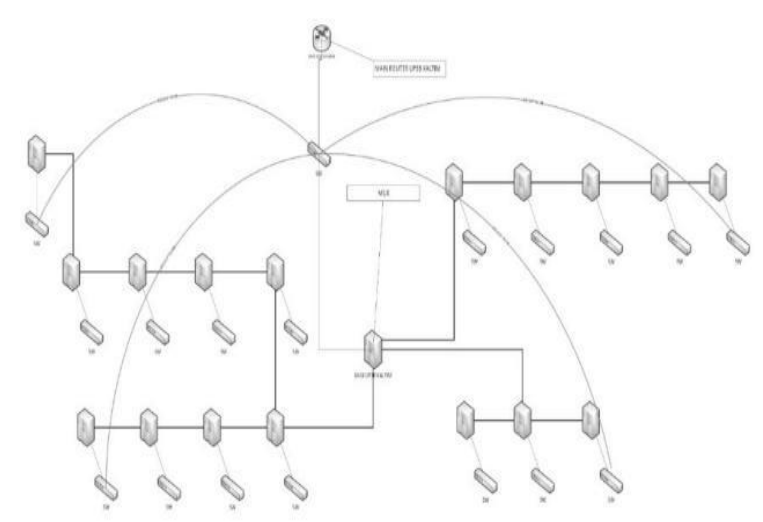

Gambar 3. Rancangan Topologi Failover [5]

Pada gambar 3 menjelaskan topologi yang dirancang dimana router yang semula terdapat pada setiap Gardu Induk difungsikan sebagai switch manageable layer 2 untuk mendistribusikan VLAN ID dari main router yang terdapat pada kantor PT PLN (persero) UP3B Kaltim selain itu juga dirancang empat jalur tambahan pada setiap gardu induk ujung sebagai jalur backup trunk vlan ketika terjadi fiber cut pada jalur utama [11].

\section{HASIL DAN PEMBAHASAN}

Hasil dari penelitian ini adalah sebuah implementasi sistem failover pada layer 2 (datalink) dengan langkah awal mengkonfigurasi Router utama yang terdapat pada PT PLN (Persero) UP3B Kaltim 
mempunyai hostname yang diberi nama MAIN_ROUTER_UP3B_KALTIM'. setelah itu membentuk beberapa VLAN di dalam router utama sekaligus menentukan port Trunk yang dibutuhkan sebagai jalur distribusi informasi nantinya

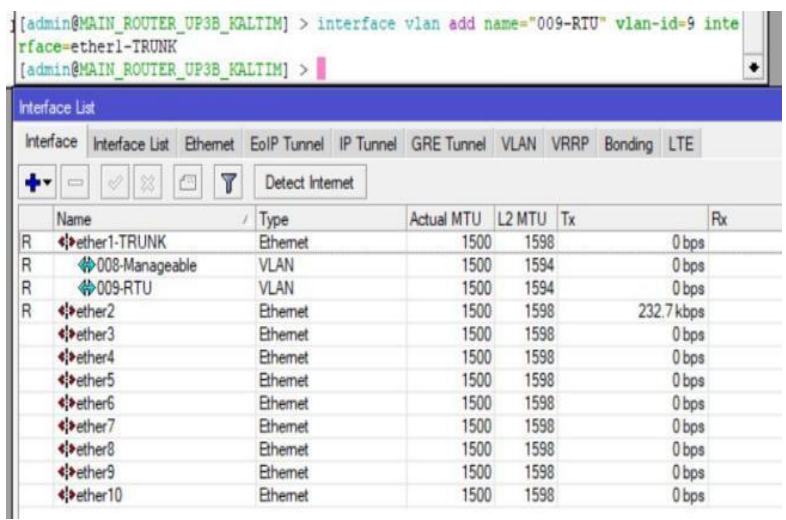

\section{Gambar 4. VLAN Pada Router Utama}

Pada gambar 5 menginformasikan daftar seluruh VLAN yang telah ditambahkan pada port TRUNK router utama [10]

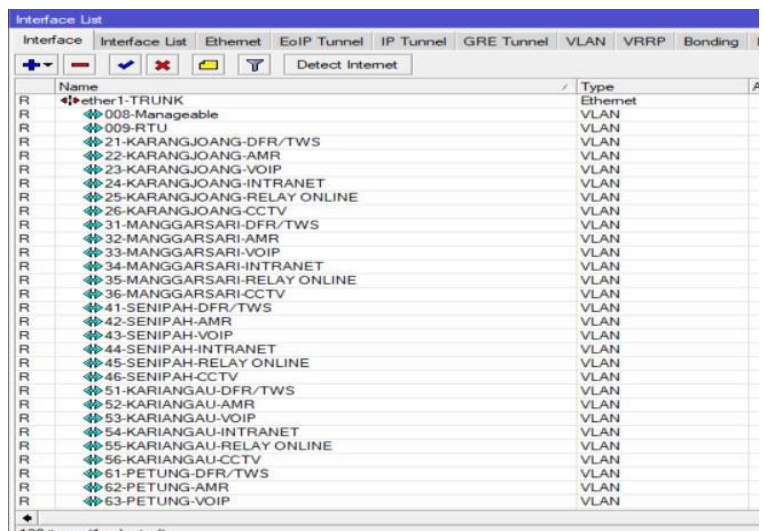

\section{Gambar 5. Informasi Trunk Pada Router} Utama

Pada switch manageable yang terdapat di PT PLN (Persero) UP3B Kaltim terdapat 6 port yang difungsikan dalam perancangan konfigurasi jaringan ini. Gambar 6 menginformasikan port switch yang telah diberikan deskripsi sebagaimana fungsinya masing-masing. Pada switch manageable, seluruh interface difungsikan mode trunk, dikarenakan pada switch ini berfungsi sebagai pendistribusian VLAN [6] dan pengaturan failover jaringan [8] dari seluruh switch yang terhubung. Sehingga tidak terdapat mode access ke peralatan, hal tersebut dapat dlihat pada gambar 7 dan Gambar 8.

\begin{tabular}{|r|l|l|l|}
\hline Entry No. & Interface & Switchport Mode & $\begin{array}{l}\text { Interface } \\
\text { VLAN Mode }\end{array}$ \\
\hline 1 & GE1 (MAIN_ROUTER) & Layer 2 & Trunk \\
\hline 2 & GE2 (FIBER_OPTIC_SAMARINDRA) & Layer 2 & Trunk \\
\hline 3 & GE3 (FIBER_OPTIC_BALIKPAPAN) & Layer 2 & Trunk \\
\hline 4 & GE4 (FIBER_OPTIC_SEBRANG) & Layer 2 & Trunk \\
\hline 5 & GE5 (BACKUP_SANGATTA) & Layer 2 & Trunk \\
6 & GE6 (BACKUP_BUKITBIRU) & Layer 2 & Trunk \\
7 & GE7 (BACKUP_INDUSTRI) & Layer 2 & Trunk \\
8 & GE8 (BACKUP_GROGOT) & Layer 2 & Trunk \\
\hline
\end{tabular}

Gambar 6. Fungsi Interface Switch Manageable

\begin{tabular}{|c|c|c|c|}
\hline \multicolumn{4}{|c|}{ Port VLAN Membership Table } \\
\hline \multicolumn{2}{|r|}{ Filter. Interface Type equals to Port $\mathbf{V}$} & \multicolumn{2}{|l|}{ Go } \\
\hline & Interface & Mode & Administrative VLANs \\
\hline 0 & GE1 (MAIN_ROUTER) & Trunk & $1 U, 2-41,5-6 T, 71,8-9 T, 10-191,20-210 T, 211-4094$ \\
\hline 0 & GE2 (FIBER_OPTIC_SAMARINDRA) & Trunk & $1 \mathrm{UI}, 5 \mathrm{~T}, 8-9 \mathrm{~T}, 101-200 \mathrm{~T}$ \\
\hline 0 & GE3 (FIBER_OPTIC_BALIKPAPAN) & Trunk & 5T, 8-9T, 21-50T, 201-210T \\
\hline 0 & GE4 (FIBER_OPTIC_SEBRANG) & Trunk & $1 \mathrm{UI}, 5 \mathrm{~T}, 8-9 \mathrm{~T}, 51-100 \mathrm{~T}$ \\
\hline 0 & GE5 (BACKUP_SANGATTA) & Trunk & $1 \mathrm{UI}, 6 \mathrm{~T}, 8-9 \mathrm{~T}, 101-200 \mathrm{~T}$ \\
\hline 0 & GE6 (BACKUP_BUKITBIRU) & Trunk & $1 \mathrm{UI}, 6 \mathrm{~T}, 8-9 \mathrm{~T}, 101-200 \mathrm{~T}$ \\
\hline 0 & GE7 (BACKUP_INDUSTRI) & Trunk & $1 \mathrm{UI}, 6 \mathrm{~T}, 8-9 \mathrm{~T}, 21-50 \mathrm{~T}, 201-210 \mathrm{~T}$ \\
\hline 0 & GE8 (BACKUP_GROGOT) & Trunk & 1UI, 6T, 8-9T, 51-100T \\
\hline
\end{tabular}

Gambar 7. Konfigurasi VLAN Interface

\begin{tabular}{|c|c|c|c|}
\hline O & 1 & GE1 (MAIN_ROUTER) & 1000M-Copper \\
\hline O & 2 & GE2 (FIBER_OPTIC_SAMARINDRA) & 1000M-Copper \\
\hline 0 & 3 & GE3 (FIBER_OPTIC_BALIKPAPAN) & 1000M-Copper \\
\hline O & 4 & GE4 (FIBER_OPTIC_SEBRANG) & 1000M-Copper \\
\hline $\mathrm{O}$ & 5 & GE5 (BACKUP_SANGATTA) & 1000M-Copper \\
\hline O & 6 & GE6 (BACKUP_BUKITBIRU) & 1000M-Copper \\
\hline O & 7 & GE7 (BACKUP_INDUSTRI) & 1000M-Copper \\
\hline 0 & 8 & GE8 (BACKUP_GROGOT) & 1000M-Copper \\
\hline
\end{tabular}

\section{Gambar 8. Deskripsi Interface Switch Pada} Switch Manageable

Pada gambar 6, 7 dan 8 menginformasikan bahwa pada port GE1 secara administrative VLAN yang ditambahkan yaitu seluruh VLAN yang terdapat pada jaringan, dikarenakan port tersebut merupakan port utama yang terhubung ke router utama PT PLN (Persero) UP3B Kaltim sehingga seluruh vlan harus ditambahkan. Pada port GE2, GE3 dan GE4 
yang merupakan port utama penghubung switch di seluruh GI melalui fiber optic juga diatur untuk VLAN GI sesuai daerahnya yaitu Samarinda, Balikpapan dan Sebrang. Port GE5 yang difungsikan untuk backup GI Sangatta hanya melewatkan VLAN dengan id tertentu, yaitu VLAN GI Sangatta, Telukpandan, Muara Badak, Sambutan, Bukuan, arapan Baru, Tengkawang, Embalut dan Bukit biru demikian juga dengan port GE6 yang difungsikan backup sisi GI Bukit biru. Untuk Port GE7 Backup link GI Industri hanya melewatkan VLAN GI Karangjoang, GI Senipah dan Gi Manggarsari. Sedangkan Port GE8 hanya melewatkan vlan GI Kariangau, GI Longikis, GI Petung, GI Kuaro dan GI Grogot. Konfigurasi Spanning Tree [9]

Switch manageable yang terdapat di kantor PT PLN (Persero) UP3B Kaltim dilakukan konfigurasi untuk spanning tree yang bertugas melakukan penentuan jalur yang aktif pada port ethernet dan melakukan disable port pada jalur stanby. Gambar 9 menginformasikan konfigurasi spanning tree pada switch manageable.

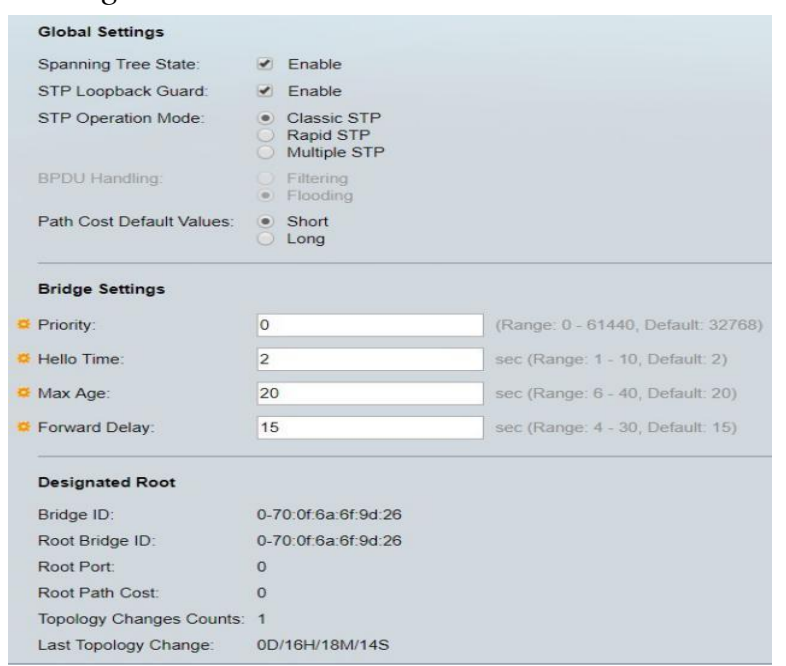

Gambar 9. Konfigurasi Spanning Tree Switch Manageable
Sesuai dengan rencana konfigurasi, pada switch manageable yang terdapat di kantor PT PLN (Persero) UP3B Kaltim menggunakan priority 0 dimana priority terkecil akan menjadi prioritas dan akan menjadi root bridge bagi seluruh switch yang terhubung. Sedangkan pada gambar dibawah menginformasikan konfigurasi Spanning Tree pada interface masing-masing yang terhubung.

\subsection{Pengujian Sistem}

Salah satu contoh pengujian sistem yaitu dengan melakukan pemutusan pada link fiber optic GE3 switch manageable PLN UP3B Kaltim atau port arah fiber optic Balikpapan. ketika terjadi down pada link GE4 switch manageable area Balikpapan maka link komunikasi dari maupun ke Balikpapan akan mengalami down sesaat hingga switch GI Industri melakukan failover jaringan melalui link backup, hal tersebut dapat dilihat pada gambar 10 dimana secara otomatis router akan mengirimkan notifikasi melalui netwatch ke telegram dan menginformasikan kondisi yang terjadi.

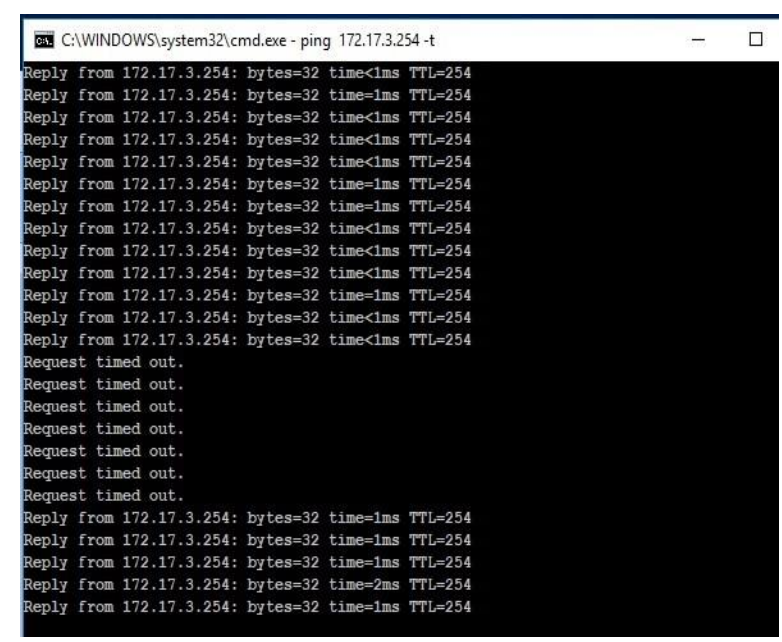

Gambar 10.Koneksi Dwon Beberapa Saat Ketika Proses Failover Area Balikpapan 


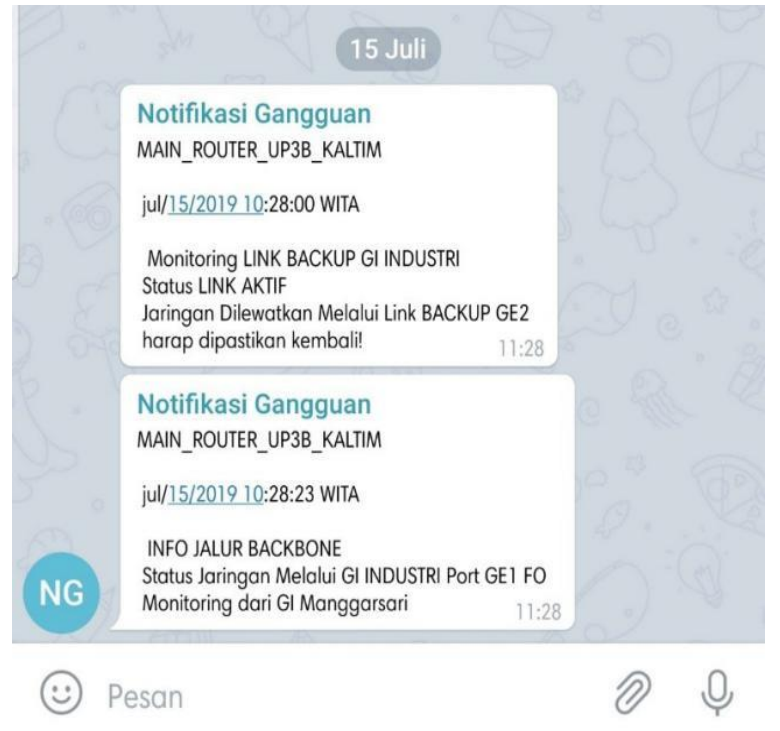

\section{Gambar 11. Notifikasi Telegram Ketika Terjadi Putus FO Arah Balikpapan}

Pada gambar 11 merupakan notifikasi yang diterima user melalui aplikasi telegram yang menjelaskan kondisi yang terjadi.

\begin{tabular}{|c|c|c|c|c|}
\hline Interface & STP Edge Por & PantRole & 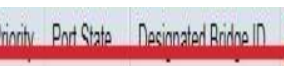 & Designate \\
\hline GEI FIBER OPTIC) & Enabled Disabled & Designated & 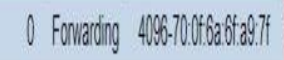 & 0.1 \\
\hline GE2(BACKUP) & Enabled Disaded & Root & 16 Fonvaring 0.70.0foabftod:20 & 647 \\
\hline GES/RTU| & Enabled Disaded & Disale & 128 Disaded NA & NA \\
\hline
\end{tabular}

\section{Gambar 12. Status Spanning Tree Pada GI Industri Pengujian Failover Area Balikpapan}

Pada gambar 12 status spanning tree yang terdapat pada GI Industri yaitu pada port GE1 yang semula pada kondisi normal adalah root menjadi designated dan forwarding dikarenakan switch GI Industri menjadi root bridge dari switch yang terdapat pada GI area Balikpapan melalui port GE1 switch GI Industri. Pada switch GI Industri memiliki bridge priority 4096. Bridge priority tersebut lebih rendah dibandingkan dengan bridge priority switch GI lain yang terdapat pada area Balikpapan karena dasar itulah switch GI
Industri dijadikan root bridge oleh switch lain. Pada port GE2 switch GI Industri status berubah menjadi root port dikarenakan pada GE2 terhubung dengan link backup switch manageable yang terdapat pada kantor PLN UP3B Kaltim yang memiliki bridge id 0 sehingga dijadikan root bridge oleh switch GI industri.

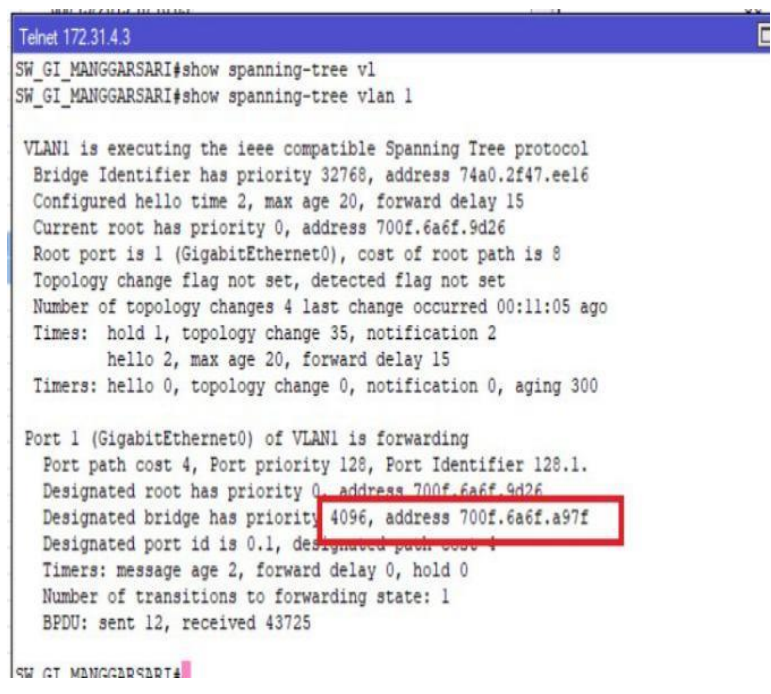

\section{Gambar 13. Status Spanning Tree Pada Switch GI Manggarsari}

Pada gambar 13 menginformasikan status spanning tree yang terdapat pada GI Manggarsari yaitu memiliki designated bridge id 4096-700f.6a6f.a97f yang merupakan bridge id pada switch GI Industri. Sehingga pada GI Manggarsari ketika terjadi putus fiber optic arah area Balikpapan akan dilewatkan melalui switch GI Industri. [11]

\section{KESIMPULAN}

Implementasi jaringan failover dapat menjaga keandalan sistem jaringan PT PLN (Persero) UP3B Kaltim ketika terjadi fiber cut atau terputusanya jaringan backbone utama dan 
secara otomatis akan melakukan failover pada jalur backup, hal ini terbukti bahwa failover juga dapat diterapkan pada layer 2 (data link) sebagai alternatif penggunaan di layer 3 (network) pada umumnya.

\section{SARAN}

Sebagai pengembangan yang masih dapat dilakukan dalam perancangan jaringan ini yaitu ketika kondisi terputusnya fiber optic area Samarinda maka switch seluruh gardu induk kecuali GI Sangatta akan melewatkan melalui switch GI Buki Biru dikarenakan pada switch GI Bukit Biru memiliki bridge priority lebih kecil dibandingkan dengan bridge priority pada switch GI Sangatta. Ketika hal tersebut terjadi maka seluruh traffic atau beban jaringan akan dilewatkan melalui backup link GI Bukit Biru. Selain itu dimasa yang akan datang diharapkan dapat ditemukan mekanisme baru untuk menyeimbangkan beban jaringan sebagian melalui GI Bukit Biru dan sebagian melalui GI Sangatta supaya terjadi penyeimbangan beban.

\section{UCAPAN TERIMA KASIH}

Terima kasih kepada Direktorat Riset dan Pengabdian Masyarakat Direktorat Jenderal Penguatan Riset dan Pengembangan Kementerian Riset, Teknologi, dan Pendidikan Tinggi sesuai dengan Kontrak Penelitian Tahun Anggaran 2020

\section{DAFTAR PUSTAKA}

[1] Komputer, Wahana., 2004, Kamus Istilah Internet, Edisi II, Andi, Yogyakarta.

[2] Arifin, Hasnul. 2011. Kitab Suci Jaringan Komputer dan Koneksi Internet. Yogyakarta: Mediakom.

[3] Towidjojo, Rendra. 2013. Mikrotik Kungfu: Kitab 2. Jakarta : Jasakom.

[4] Athailah. 2013. Mikrotik Untuk Pemula. Jakarta: Mediakita.

[5] Asteria, Devita.2015. Implementasi Dan Analisis Metode Failoverpada Sistem Redundant Dedicated Server Dan Cloud Server Untuk Layanan VOIP, E-Proceeding of Engineering, Vol.2 No.2 pp.3137-3144, Agustus 2015.

[6] Choirullah, Muhammad Yusuf.2016. Analisis Kualitas Layanan Virtual Router Redundancy Protocol Menggunakan Mikrotik pada Jaringan VLAN, JNTETI, Vol. 5, No. 4, pp.278-285, November 2016

[7] Sofana, Iwan. 2013. Teori dan Modul Praktikum Jaringan Komputer. Bandung: Modula.

[8] Arifin, Hasnul. 2011. Kitab Suci Jaringan Komputer dan Koneksi Internet. Yogyakarta: Mediakom.

[9] Peniarsih, Rancangan Sistem Jaringan Stp (Spanning Tree Protocol) Berbasis VLAN [Online]. Available: http://journal.universitassuryadarma.ac.id/in dex.php/jsi/article/view/39/37, diakses tanggal 30 Maret 2019.

[10] Dewi, Sari, Yuliantama, Penerapan Jaringan LAN Dengan Sistem Redudancy Static Route Menggunakan Router Mikrotik Pada PT Sistem Aksesindo, [Online]. Available: http:/ejournal.bsi.ac.id/ejurnal/index.ph p/evolusi/article/view/3589, diakses tanggal 30 Maret 2019.

[11] Sadikin, Nanang, Faprianda Rossy Ramadhan, Implementasi Load Balancing 2 (Dua) ISP Menggunakan Metode Per Connection Classifier (PCC), [Online] Available:

https://repository.usd.ac.id/18613/2/115314 056 full.pdf, diakses tanggal 30 Maret 2019 . 